\title{
Lapurdum
}

Euskal ikerketen aldizkaria | Revue d'études basques |

Revista de estudios vascos | Basque studies review

$10 \mid 2005$

Numéro X

\section{Evolución y actualidad de la literatura infantil y juvenil en lengua vasca}

Mari Jose Olaziregi

\section{(Q) OpenEdition \\ Journals}

Edición electrónica

URL: http://journals.openedition.org/lapurdum/53

DOI: 10.4000/lapurdum.53

ISSN: 1965-0655

\section{Editor}

IKER

Edición impresa

Fecha de publicación: 31 diciembre 2005

Paginación: 137-152

ISBN: 2-86781-409-X

ISSN: $1273-3830$

Referencia electrónica

Mari Jose Olaziregi, «Evolución y actualidad de la literatura infantil y juvenil en lengua vasca », Lapurdum [En línea], 10 | 2005, Publicado el 01 abril 2008, consultado el 10 diciembre 2020. URL : http://journals.openedition.org/lapurdum/53 ; DOI : https://doi.org/10.4000/lapurdum.53 


\section{Evolución y actualidad de la literatura infantil y juvenil en lengua vasca. Mari Jose Olaziregi (Universidad del País Vasco. Facultad de Filología, Geografía e Historia. Vitoria-Gasteiz)}

\section{Algunas consideraciones en torno a la literatura infantil y juvenil.}

Como es sabido, toda actividad literaria necesita de un discurso crítico-teórico que la legitime. El hecho de que desde la universidad o desde otros ámbitos organicemos cursos, seminarios o congresos sobre $\mathrm{LIJ}^{1}$ no deja de ser más que un intento más para que esa literatura que hasta incluso en época reciente ha sido cuestionada por algunos, sea homogeneizada a la literatura con mayúsculas, es decir, a la literatura de adultos. Seguramente, ha sido el hecho de que la LIJ desde sus orígenes se haya desarrollado a expensas o gracias a la institución educativa lo que ha propiciado el retraso de dicha legitimación crítico-teórica (cf. Shavit, Z., Poetics of Children's Literature, The University of Georgia Press, Athens and London, 1986: 137). La defensa que autores como Jorge Luis Borges hicieran sobre la LIJ, o la que críticos como Harold Bloom han realizado recientemente en su conocido: Relatos y poemas para niños extremadamente inteligentes de todas las edades (Anagrama, 2003), son sólo algunos ejemplos de los intentos que la literatura infantil y juvenil está realizando para salir del ámbito marginal, periférico diría I. Even Zohar, que ocupa en los diferentes sistemas literarios. A estas reivindicaciones habría que añadir la clara evolución que los estudios de literatura infantil y juvenil han tenido en el ámbito académico reciente gracias, entre otros, a la aplicación de metodologías ampliamente aceptadas por la crítica literaria contemporánea.

Y ya que hablamos de cánones y de posicionamientos dentro del sistema literario, tendríamos que comenzar puntualizando que la LIJ en lengua vasca ocupa todavía un lugar bastante periférico en el actual star-system literario español ${ }^{2}$. Datos como que sólo 3 autores vascos, Bernardo Atxaga, Juan Kruz Igerabide y Mariasun Landa, hayan sido incluidos en un listado canónico de 100 obras de la LIJ (véase El País 5-4-2003), o que sólo un autor vasco haya ganado el Premio Nacional de LIJ (Mariasun Landa, en 2003, por Un cocodrilo bajo la cama) son síntomas de lo que venimos diciendo. Pero estas reflexiones no serían del todo exactas si no tuviéramos en consideración el reconocimiento que la LIJ en lengua vasca en general, y algunos de sus autores en particular, han tenido en la última década. Los recientes premios a autores vascos así lo confirman(Premio Abril-2003 a Joanes Urkixo; Premio Leer es Vivir-2003 a Felipe Juaristi, Premio Lazarillo-2002 a Laida Martínez...).

Supongo que son ejemplos que cuestionan, en parte, el aislamiento de la LIJ en lengua vasca, aislamiento, sea dicho de paso, también promovido por la debilidad del propio sistema literario vasco. La tardía convocatoria de ayudas a la traducción de obras en euskara a otras lenguas por parte de las instituciones vascas (el año 2000 salió a la luz la primera convocatoria de ayudas a la traducción por parte del Gobierno Vasco), la reciente creación de organizaciones, como Galtzagorri Elkartea (1990-) cuyo objetivo es

\footnotetext{
${ }^{1}$ LIJ: literatura infantil y juvenil.

${ }^{2}$ Dicha marginalidad es mucho más manifiesta en el sistema literario francés. Aunque la recepción crítica que han tenido las traducciones de Bernardo Atxaga y Mariasun Landa hayan sido excelentes, la presencia e importancia que la literatura escrita en nuestra lengua tiene en el ámbito literario francés es mínima.
} 
la promoción y difusión de la LIJ en lengua vasca, o la inexistente presencia de asignaturas de LIJ en las facultades de Filología de Euskadi, son algunas de las causas que han podido alimentar nuestro aislamiento. En la parte positiva, tendríamos que mencionar, sin duda, la instauración, a partir de 1981, de los estudios de Filología Vasca en las universidades vascas, lo que ha permitido la proliferación de tesis doctorales sobre LIJ en lengua vasca. Ahí están, por ejemplo, la tesis defendida por Xabier Etxaniz en 1996, tesis que planteaba una historiografía de la LIJ en euskara; la realizada por Eukene Martín en 1997, y que analizó la invención de la infancia en los cuentos de 1976 a 1990; la realizada por Manu López en torno a la LIJ traducida al euskara, o tesis que han aplicado una metodología crítica concreta al análisis de obras literarias, como la que realicé yo misma en 1996, en torno a la obra de Bernardo Atxaga (cf. Leyendo a Bernardo Atxaga, Universidad del País Vasco, 2002) ${ }^{3}$. Todos ellos son una muestra, junto a los datos que comentaremos en el segundo apartado de este artículo, del intento que está realizando nuestra literatura para superar la marginalidad, sea dentro de los sistemas literarios español y francés, sea en el propio sistema literario vasco.

\section{Literatura vasca y vida literaria.}

En las líneas que siguen, trataremos que esbozar la evolución sociohistórica de la literatura infantil y juvenil escrita en lengua vasca para, a continuación, detenernos en los autores contemporáneos más reseñables. Trataremos, en definitiva, de perfilar la evolución de la vida literaria vasca haciendo nuestra una visión multidisciplinar de la historia de la literatura, donde a partir de las aportaciones de la sociología empírica de la literatura, trataremos que inscribir esa vida literaria en el sistema más amplio de la vida cultural y social. Serán las conclusiones de cuatro estudios las que guiarán nuestro recorrido. Por un lado, los estudios sociológicos (J.M. Torrealdai:1997; M.J. Olaziregi:1998), por otro, las aportaciones historiográficas (X. Etxaniz: 1997; E. Uria: 2000; M. López Gaseni:2004) o los estudios en torno a la LIJ traducida (M. López Gaseni: 2000).

Tal y como recordábamos en un número anterior de esta revista ${ }^{4}$, nuestro autor contemporáneo más universal, Bernardo Atxaga, comparaba la literatura vasca con un erizo que ha estado demasiado tiempo en letargo, pero que, afortunadamente, ha conseguido despertar en el siglo $\mathrm{XX}^{5}$. El período más interesante y reseñable de nuestra

\footnotetext{
3 Todas estas tesis doctorales han sido realizadas en la Universidad del País VascoEuskal Herriko Unibertsitatea.

4 Cf. Olaziregi, M.J., 2001, “Et...le hérisson se réveilla: passé et présent de la littérature basque”, Lapurdum VI, 205-217.

${ }^{5}$ Escribo en una lengua extraña. Sus verbos, la estructura de sus oraciones de relativo, las palabras con que designa las cosas antiguas

- los ríos, las plantas, los pájaros-

no tienen hermanas en ningún otro lugar de la Tierra.

Casa se dice etxe; abeja erle; muerte heriotz.

El sol de los largos inviernos, eguzki o eki:

el sol de las suaves y lluviosas primaveras,

también eguzki o eki, como es natural;

Es una lengua extraña, pero no tanto.

Nacida, dicen, en la época de los megalitos

sobrevivió, lengua terca, retirándose,
} 
historia literaria se concentra, por tanto, en los últimos cien años y son éstos precisamente los que ocuparán la mayoría de las líneas de esta introducción. Por ello, serán escasas las referencias que haremos a nuestro pasado literario más remoto ya que, desde que en 1545 sale a la luz el primer libro en euskara, el poemario Linguae Vasconum Primitiae de B. Etxepare, son sólo 101 los libros se publican hasta 1879 y además, de entre ellos, sólo 4 pueden ser considerados estrictamente literarios. Es precisamente uno de ellos, Ipuin onak de Bizenta Mogel (1804),el que puede ser considerado como el primer texto de literatura infantil y juvenil. Vemos, por tanto, que hablamos de una literatura tardía, de una literatura que no ha tenido condiciones sociohistóricas demasiado favorables para desarrollarse y que ha estado ligada, como es obvio, a los avatares de la lengua que la sustenta: el euskara.

Y ya que hablamos del euskara, tendríamos que precisar que en la actualidad es hablada por unos 700.000 euskaldunes, o vascoparlantes, que viven a ambos lados del Pirineo. La frontera política que divide hoy en día el País Vasco, o Euskal Herria, determina, a su vez, una situación legal diferente. Si, tras la aprobación de la Constitución Española de 1978, el euskara tiene, junto al castellano, un status de oficialidad en las dos comunidades autónomas de la zona española, no ocurre lo mismo en el País Vasco francés, donde el euskara no tiene carácter de lengua oficial. Las consecuencias de esta desigualdad son fácilmente predecibles: la instauración de modelos bilingües de enseñanza o la convocatoria de ayudas a la edición en euskara han hecho que, en la actualidad, el sistema literario vasco sea más fuerte y dinámico en el País Vasco español que en la zona continental.

\section{2.a) Inicios de la literatura infantil y juvenil en euskara. Desde los orígenes hasta 1935.}

La Fuerte pujanza económica y cultural que conoció la zona vasco-francesa hasta el s. XVII permitió, entre otras cosas, que se dieran las mejores condiciones para que las primeras publicaciones de nuestra historia literaria vieran la luz. Hablamos de una época en la que no era fácil publicar en euskara, época en la que 3 de cada 4 libros

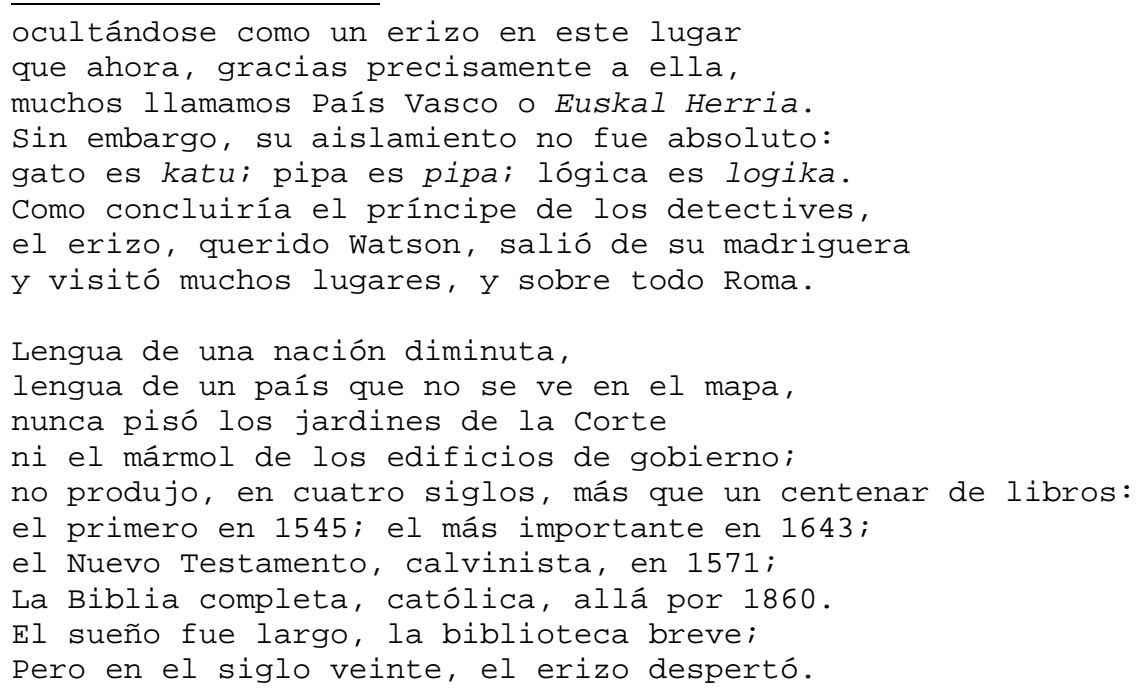

(Bernardo Atxaga, Nueva Etiopía, El Europeo, 1996) 
eran impresos fuera de las fronteras de Euskadi. Al texto de B. Etxepare de 1545 siguieron otros que se convirtieron en puntos de inflexión importantes en el desarrollo de la literatura en lengua vasca. Nos referimos a la traducción, en 1571, del Nuevo Testamento y escritos calvinistas realizada por J. de Leizarraga, a la aparición, en 1643, del Gero de Pedro de Axular, considerada como un excelente exponente de la prosa ascética en nuestra lengua, o a los poemas y proverbios que A. Oihenart compiló en su libro Les proverbes Basques...(1657), por citar sólo unos ejemplos. A todo este listado de obras, tendríamos de añadir el reciente hallazgo del manuscrito de J.P. Lazarraga, hallazgo no sólo relevante por la antigüedad del manuscrito (1564-67), sino porque este texto escrito en la variante alavesa se ha convertido en el más antiguo de la zona peninsular. La publicación de textos de edificación y de traducciones continúa, y en el siglo XVIII, es la zona vasco-española la que conoce un resurgir de obras y autores, gracias, entre otras razones, a una situación socio-económica que favorece las condiciones para la creación. Surge la "Real Compañía Guipuzcoana de Caracas" (1728), así como la Real Sociedad Vascongada de Amigos del País (1765) y el Real Seminario de Bergara. No obstante, el perfil de la mayoría de los escritores sigue siendo religioso. Al amparo de las ideas de la Ilustración, autores como Xabier M. Munibe, Conde de Peñaflorida, impulsaron y avivaron el ambiente cultural de la época, aunque bien es cierto que la mayoría de las manifestaciones culturales se realizaban en castellano. Destacaríamos los primeros textos dramáticos cultos que aparecen de la mano de I. Barrutia (Acto para la Nochebuena, no publicado hasta 1897) y X.M. Munibe, conde de Peñaflorida (El borracho burlado, (1762)). En ambas es constatable la utilización del castellano, ya que no hay que olvidar que la escolarización se daba en castellano en la zona peninsular (Ley Moyano, 1857; utilización del anillo para castigar a los alumnos que hablaban en euskara...) y que el euskara vivía una situación diglósica: la cultura se vehiculaba en castellano, la doctrina en euskara. Según datos de J.M. Torrealdai (1997), el 60\% de las obras que se publican entre 1700 y 1875 se publican en Gipuzkoa. Es en el s. XIX, cuando, a la sombra de las ideas del romanticismo, nuestro país y nuestra lengua suscita gran interés, sea entre lingüistas, políticos o estudiosos de la talla de W. von Humboldt, L.L. Bonaparte, A. D'Abbadie, W. Webster, H. Schuchardt, J. Van Eys... o entre escritores como el poeta inglés W. Wordsworth o el escritor francés P. Merimée, quien nos presenta un personaje vasco, Carmen, como heroína de su conocida novela.

El primer libro de literatura infantil y juvenil en lengua vasca, Ipuin onak, hizo su aparición en 1804, escrito por Bizenta Mogel (1782-1854). También supuso la primera publicación literaria en una tradición dominada por hombres. Aunque el objetivo didáctico-moralista sea el que prevalece en el texto, resaltaríamos la importancia del libro como exponente de un nuevo tipo de narración y como exponente, a su vez, de un nuevo tipo de lectura más literaria pero alejada todavía de objetivos estrictamente estéticos. Ipuin onak, es en realidad, una traducción y adaptación de las fábulas de Esopo, será el punto de partida para la aparición de toda una serie de fabulistas, aunque en la mayoría de los casos, será el verso la forma predominante. El caso de Bizenta es absolutamente excepcional, pues se estima que sólo el 15 \% de las mujeres de la época estaban alfabetizadas. En su caso se cumplieron las condiciones que V. Woolf describió en las escritoras del XIX: un matrimonio tardío y carencia de hijos. Tras el Concilio de Trento, las mujeres eran vistas como portadoras de la tentación. El panorama literario vasco, protagonizado por curas, fue, seguramente, un ámbito cerrado para las mujeres durante demasiados siglos. Los prólogos que conocieron las diferentes ediciones del 
libro de Bizenta Mogel, como el escrito por Domingo Agirre, el novelista costumbrista y autor canónico de la primera mitad del s. XX, reflejan claramente los prejuicios contra las mujeres letradas. Es importante constatar que Bizenta se adscribió a uno de los modelos educativos, el de Locke, quien primaba el uso de las fábulas para la educación, que fueron imponiéndose a partir del XVII. Como es sabido, el surgimiento del sistema literario de LIJ en el s. XVIII fue posible al desarrollo de las diferentes teorías de la educación en el siglo anterior. Otras obras que siguieron la senda didáctica-moralista abierta por B. Mogel fueron: Fábulas y otras composiciones en verso bascongado, dialecto guipuzcoano de A. Iturriaga (1842) (traducción de 55 fábulas de Samaniego), La Fontainaren aleghia berheziak (1848) de J.B. Archu Fableac edo Aleguiac (1852)de L. Goyhetche, estas últimas traducciones de las fábulas de La Fontaine. Es importante reseñar la novedad de estos textos en tanto que sirvieron para romper en parte la preeminencia de textos religiosos en la literatura vasca y para incidir en un grupo de lectores potenciales, los infantiles y jóvenes, poco atendidos hasta la fecha. Los intentos del pedagogo y escritor A. Iturriaga por promover la enseñanza en lengua vasca nos hablan de una realidad lingüística diglósica y de las dificultades que todo ello suponía para el desarrollo de una literatura en lengua vasca.

En cualquier caso, es en el último decenio del siglo XX cuando se dan las primeras señales de un espíritu nuevo, espíritu que transformará de raíz, el futuro de la literatura en lengua vasca. Así, desaparece el antiguo predominio de obras de edificación y formación religiosa, y el espectro de géneros literarios cultivados se va ampliando: la trayectoria de poetas como Bilintx o Etxahun se verá enriquecida por la incorporación de nuevos autores como Arrese Beitia y el género narrativo, en especial, la novela, hará su irrupción en el panorama literario vasco. Esta producción poética se verá impulsada por la proliferación de los Juegos Florales, que comenzaron a celebrarse en la zona continental en 1851 y en la peninsular en 1879. Podríamos señalar a la pérdida de los fueros tras la segunda guerra carlista (1873-1876) como el hecho político que señaló el comienzo de lo que la crítica ha denominado el "Renacimiento" literario vasco. Es en esta época cuando, de la mano de Sabino Arana (1865-1903), se sentarán las bases del nacionalismo vasco que, a su vez, influirá en toda la literatura vasca del primer tercio del siglo XX (en 1895 se funda el PNV). La preeminencia de la ideología nacionalista hará que la producción literaria de las primeras décadas del s. XX esté condicionada de nuevo por objetivos extraliterarios. La novela vasca que inicia su andadura a finales XIX de la mano de D. Agirre tratará de reflejar un mundo idealizado y esencialista, alejado de las ciudades industriales que se fueron conformando en el País Vasco. Se trata, en definitiva, de una novela de tesis en torno a tres grandes ejes: fe, patriotismo y vasquidad, cuyo modelo perdurará en la narrativa vasca hasta los años 50.

Junto a la fuerte industrialización que se da en el último tercio del XIX (recordemos que es entonces cuando, sobre todo en Bizkaia, surge la gran siderurgia y los Altos Hornos de Bilbao), el aumento de las tasas de escolarización o el surgimiento de diferentes revistas literarias hicieron que el número de lectores se fuera incrementando. Se calcula que entre 1876 y 1936 se crearon unas 140 publicaciones periódicas (almanaques, semanarios, anuarios...), lo cual es un indicativo de la vitalidad cultural de la época. A pesar de ello, habría que señalar que esta masa de lectores no era tan grande como se pudiera suponer. Los hablantes euskaldunes no estaban habituados a la lectura silenciosa e intensiva que requerían las novelas y relatos que iban surgiendo, y además hay que subrayar que la escolarización se daba, sobre todo, en castellano. La literatura fuerista que fue surgiendo tras la abolición de los fueros en 1876 presentaba 
un claro tono nostálgico por un pasado foral y noble, y se sustentaba en leyendas que fueron alimentando el imaginario nacionalista. Navarro Villoslada, A. Araquistain...pero sobre todo A. Trueba tuvieron gran importancia. Es precisamente en uno de los relatos de Trueba (El Judas de la casa) en el que se inspira A. Apaolaza en su novela corta Patxiko Txerren (1890), novela moralista de ambiente rural que tuvo buena acogida entre los jóvenes. La influencia de la ideología y el imaginario nacionalista son importantes en el género más popular de aquel tiempo, el género dramático, que suponía el 51 \% de los textos literarios que se editaban. Autores como M. Soroa o T. Altzaga lograron acercarse mucho más al lectorado vasco cuyos hábitos de lectura en euskara eran muy bajos. En 1918, surge el cómic “Teles eta Miko”, que se convertirá en un acicate importante para los ilustradores de la época, entre los que mencionaremos a A. Jauregibeitia, autor de las ilustraciones de los cuentos de Oscar Wilde y de los hermanos Grimm, traducidos y publicados, como se indica más adelante, a finales de los años 20 (cf. Etxaniz: 1997). En 1918 surgen, además, dos instituciones que tendrán gran importancia en el asentamiento de la cultura en lengua vasca: La Sociedad de Estudios Vascos-Eusko Ikaskuntza y Euskaltzaindia-Real Academia de la Lengua Vasca.

El reducido número de escuelas vascas que surge a finales del XIX, se irá conformando con la aparición de las escuelas de barrio que a partir de 1920 pusieron en marcha las Diputaciones y con la multiplicación de ikastolas en las décadas 20-30. Incluso el propio S. Arana publicó en su día, en 1897, una gramática para que los niños aprendieran a leer en vizcaíno (Umiaren lenengo aizkidia. Bizkaiko euzkeraz irakurtzen ikasteko). Quedan como ejemplo del esfuerzo que se estaba haciendo en la enseñanza del euskara, los libros que a partir de 1907 publicó el editor I. López de Mendizábal, entre los cuales mencionaremos a Xabiertxo (1925) y a Umearen laguna (1920), libros que fueron ilustrados por John Zabalo Ballarin "Txiki” (1892-1948) (cf. E. Uria: 2000) y que siguieron funcionando entre los escolares hasta bien entrados los sesenta. También le debemos a Isaac López de Mendizábal la creación del cómic Poxpolin (1935-1936).

La literatura dedicada a los niños era, mayoritariamente, didáctica (de objetivo moralista, religioso, como Umiak Autortuten eta Jaunartuten (1911) de I. Arrandiaga, o patriótico, como Margeritéren ames ixukorra de J. Guzekitz (1914)). Más interesantes resultan, en cambio, los 19 cuentos que se incluyen en Ipuin laburrak umetxoentzat (1922), de B. Garitaonandia, o la primera obra dramática publicada para niños, Nekane edo Neskutzaren Babesa (1922) de la escritora Tene Mujika. Al igual que otras mujeres que escribieron en las revistas de la época, los textos de Mujika eran próximos a los de la ideología nacionalista, para quien catolicismo y defensa del euskara eran los objetivos primordiales. El perfil biográfico de Tene Mujika, en tanto integrante del Emakume Abertzale Batza (Grupo de Mujeres Nacionalistas) se corresponde con el de las mujeres nacionalistas de la época que tuvieron un papel importante en la actividad cultural.

Por otro lado, aunque a priori menos ambicioso que las novelas costumbristas de la época, el relato breve costumbrista que se publicó en esta época logró conectar con los lectores vascos mucho más que aquellas. No eran obras escritas para niños, pero digamos que fueron "ganadas" por ellos. Nos referimos a los libros de narraciones breves Abarrak (1918) y Bigarren Abarrak (1930) de Ebaristo Bustintza "Kirikiño" (1866-1929). Los relatos de Kirikiño utilizan técnicas de narración oral y son, básicamente, humorísticas. A pesar de estar inscritas en la poética costumbrista y estar 
por ello supeditadas a las condiciones propias del género (narrador omnisciente autorial, personajes poco desarrollados, moralidad y didactismo del texto, humor basado en tópicas caracterizaciones de personajes-tipo), los cuentos de Kirikiño junto al conocido Pernando Amezketarra. Bere ateraldi eta gertaerak (1927) de G. Mujika, tienen el mérito de haber desarrollado una prosa fluida, alejada del influjo purista y que conectó con los lectores potenciales que prefiguraba este tipo de relato tradicionalista, los lectores del ámbito rural. También se publicaron en aquellos años, otras compilaciones que recogían relatos y cuentos tradicionales vascos, como Dar-Dar-Dar o Txomin Arlote (1922) bien ilustrados por Txiki, Supazter xokoan (1924) de J. Barbier, Amattoren uzta. La moisson de Grand'Mère (1934) de Mayi Ariztia, etc. En cuanto a las traducciones, subrayaremos las dos traducciones de cuentos tradicionales de los hermanos Grimm (Ipuiñak, trad. Por J. Altuna y Grimm Anaien Berrogeitamar UmeIpuin, traducido por J.A. Larrakoetxea, ambas en 1929), la de textos reconocidos de corte didáctico-moral (Schmid), la de O. Wilde Printze zoriontsua eta beste ipuin batzuk (1927), o la de El lazarillo de Tormes (Tormesko itsu-mutila) por el escritor y traductor N. Ormaetxea, Orixe. Según subraya M. López Gaseni (2000), las obras que se traducen en el período 1876-1935 poseen las siguientes características: a) entre los títulos traducidos prevalece la denominada "literatura ganada"; b) no se aprecia ninguna sistematización en la selección de las lenguas que se traducen; c) la función que prevalece en los textos traducidos es la didáctico-moral; d) prevalece el dialecto vizcaíno e) es clara la tendencia a adaptaciones ideológicas y didácticas.

\section{2.b) Consolidación e institucionalización de la LIJ como actividad autónoma (1936-1975). De posguerra y renacimiento.}

Al igual de lo que ocurriera en otras literaturas del ámbito ibérico, la guerra civil española trajo efectos devastadores en la producción literaria vasca. A la cantidad de bajas y de exiliados (150.000), le siguió una política represiva por parte del bando de los ganadores. Hablamos de una época en la que se prohibieron los nombres vascos e incluso las inscripciones en euskara de las lápidas de los cementerios, una época en la que la calle, la administración, la cultura... fueron ámbitos donde el franquismo ejerció su censura. Se ha afirmado que la generación de la posguerra fue una de las más importantes de la literatura vasca, pues le dio lo que más necesitaba en aquellos momentos, una continuidad. En cuanto a la literatura infantil y juvenil, es a finales de los años 40 cuando vuelven a aparecer en la zona peninsular textos para los más jóvenes. Hablamos, de nuevo, de textos religiosos (Iesus Aurraren bizitza (1948), Haurren meza, V. L. Leon (1942), Haurren-Eliz-liburutxoa, M. Lekuona (1949), Kristau- Ikasbidea Bertsotan (1950), N. Etxaniz...), o de compilaciones de cuentos tradicionales (Euskalerriaren Yakintza (1942), R.M. Azkue)... Junto a ellos, destacaremos el libro de poemas para niños Haur elhe haurrentzat (1944) del escritor Jules Moulier “Oxobi”. En cuanto a las traducciones, son mencionables el cuento Leoikumea (1948) de Orixe, texto que parece ser la adaptación-traducción de un libro ilustrado y que fue encargado por el Gobierno Vasco en el exilio; Platero eta biok (1953), traducido por B. Ametzaga Aresti y publicado en Montevideo. La editorial Itxaropena de Zarautz pone en marcha una importante colección, Kuliska, en 1952, donde se publican Noni eta Mani (1952) del escritor islandés J. Svensson, traducido por P. Mujika, o narraciones humorísticas como Purra! Purra! (1953)o Pernando Plaentxiarra (1957) de Jon Etxaide. También Euskaltzaindia se unió al esfuerzo de tratar de ampliar la escasa oferta de libros en euskara publicando textos que tuvieron buena acogida entre los jóvenes, tales como: Ipuin Barreka (1959) de F. Bilbao, 
Abarrak (1956) de Kirikiño, o Euskalerriko ipuiñak (1957), selección de cuentos populares vascos a cargo de A. Irigaray. La primera novela policíaca vasca es de aquellos años, y podemos considerarla como una obra "ganada" por los jóvenes. Nos referimos a Amabost egun Urgain'en (1955), J.A. Loidi, escrita en la línea de la novela inglesa clásica del estilo "whodunnit". Completaremos este breve repaso al lento renacer de la LIJ en los 50, recordando la colección para niños: "Umetxoen ipuiak" (1957), con historias de animales profusamente ilustradas, o la primera revista para niños: Umeen Deia (1959) de F. Murieta, publicado gracias a la institución Príncipe de Viana, que se publicó durante 7 años, mensualmente, con una totalidad de 65 números. No obstante, no generó una dinámica de lanzamiento de nuevos escritores, y se volvió a unir un objetivo patriota (euskara), con el religioso. En 1960 surge la revista Pin Pan (1960-1970), que realiza una versión vasca de personajes del cómic conocidos en la época (Mortadelo y Filemon, pasan a ser “Txorizo eta Txistorra”, o Zipi y Zape "Peru eta Txomin).

Los acontecimientos que se sucedieron en Euskadi en la década de los años 60 (desarrollo industrial y económico, afianzamiento de las ikastolas, unificación del euskara, gran activismo político contra el régimen franquista que censuraba toda actividad cultural en euskara, campañas de alfabetización...), crearon un humus propicio para la germinación de un vuelco radical en los planteamientos literarios. El mundo editorial vasco también vivió aires renovadores (surgen nuevas editoriales y se incrementa la producción), en 1965 se celebra la primera Feria del Libro Vasco en Durango, y hubo quien incluso reclamó una política editorial seria para conseguir que el euskara llegase a todos los ámbitos culturales. Hablamos de años donde la modernidad se expresaba en forma de poesía social (Harri eta Herri, G. Aresti, 1964), o en forma de novela experimental (Egunero hasten delako, R. Saizarbitoria, 1969).

En LIJ sobre todo podemos hablar de literatura escrita con objetivos estéticos, y de forma sistemática, a partir de los 60 , aunque la producción no se incrementará hasta los 70. Cabría recordar, no obstante, las compilaciones de relatos tradicionales de J.M. Barandiaran El mundo en la mente popular vasca (1962) (tomos II y III), o el libro de compilaciones y creación: Amandriaren altzoan (1961) de Julene Azpeitia. X. Etxaniz (1997) ha subrayado la importancia que tuvo, en la literatura infantil y juvenil escrita en lengua vasca, la aparición de Marijane Minaberri. Su volumen de cuentos: Itchulingo anderea... (1963) y su poemario Xoria Kantari (1965) son obras que buscan, ante todo, el placer estético de la lectura. Los cuentos son de diversa factura, aunque beben mucho de las fábulas y cuentos tradicionales. Además de los mencionados, deberíamos recordar el libro: Mendekoste Gereziak eta Beste (1963), donde se recogieron los cuentos publicados en diversas revistas por J. Etchepare. Se trata de cuentos logrados que según el escritor y editor Mujika Iraola presentan la influencia de los relatos de Grimm y Tolstoi.

Una de las integrantes del grupo Ez Dok Amairu (1965), Lourdes Iriondo, publicó en la colección "Kimu” de la Editorial Mensajero el libro de relatos Hegohaizearen ipuinak (1973), donde, al hilo de la corriente cultural de la época, se trataba de aunar tradición y modernidad (entendida como compromiso), creando relatos con sustrato tradicional, aunque enraizados en la época. También publicó un par de obras de teatro: Martín Arotza eta Jaun Deabrua (1973) y Sendagile Maltzurra (1973), donde también queda patente la utilización de canciones populares y la nueva pedagogía freinetiana que se estaba imponiendo en las ikastolas o escuelas vascas. Dicha 
pedagogía influyó, sin duda, en la publicación de obras colectivas escritas por los propios alumnos en la década de los 70.

En cuanto a las traducciones que se realizaron en décadas 60-70, recordaremos que durante 1962-1964, la editorial EDILI de Donostia publicó traducciones de cuentos tradicionales como Caperucita, Blancanieves o Cenicienta realizadas por Jon Oñatibia. Se trataba de adaptaciones para niños, con grandes ilustraciones, final feliz. J.A. Etxebarria tradujo los cuentos de Perrault en 1965 y los de Andersen en 1969. Ardo ta ogi Martxelin (Mercelino pan y vino) de J.M. Sánchez-Silva (Premio Aldersen 1968) vio la luz en 1970, traducido por J.M. Satrustegi. En la década de los 70, la colección KIMU de la editorial Mensajero incorporó la traducción de algunas novelas históricorománticas que causaron furor en décadas anteriores, tales como, Amaia, Harkaitz, elurra ari zueneko aura, Antso Gartzeiz ..., traducidas por I. Azkune y J.M. Arrieta. También la editorial Cinsa de Bilbao inició, a partir de 1974, una colección que incorporaba traducciones y adaptaciones de clásicos de la LIJ universal, como el Robinson Crusoe, traducido por Atxaga en 1974 (también se publicaron: Morgan, Sandokan, Pirataren emaztea, Mompracem azkena de Salgari, y Heidi). Otros clásicos que también fueron traducidos en esos años fueron el Printze txikia (El principito) de Saint Exúpery también fueron traducidos durante esos años. Según concluye M. López Gaseni (2000), las traducciones de LIJ al euskara durante el período 1936-1975 tienen las siguientes características: a) aparecen temas modernos como la emigración, viajes exóticos, diversidad de razas...sobre todo, en las editoriales catalanas, pero no se aprecia que esos temas influyan en la creación original en euskara. Las funciones primordiales que cumplen estas traducciones son didáctico-morales. B) la mayoría de las traducciones que se realizan en los últimos 10-15 años de este período o en los primeros del siguiente, pasan por el castellano como lengua-puente. Las adaptaciones ideológicodidácticas son frecuentes (al igual que en el período anterior) pero no en el posterior.

Los datos referentes a la producción de estos años (1936-1975) dibujan un panorama que refleja adecuadamente la lenta evolución que la LIJ en lengua vasca tuvo en el período comprendido (cf Torrealdai, J.M.: 1997): con una infraestructura editorial que se concentraba, sobre todo, en la zona peninsular (73,6 \%), la presencia social del libro vasco era escasa y la mayoría de los agentes editoriales eran amateurs. Los nuevos títulos ocupaban el 93 \% de lo editado, y entre ellos, las novedades surgidas en euskara suponían el 77,7 \%. Del total de 1.626 novedades que se publicaron en esos años, el porcentaje de libros traducidos ascendía a 22,3 \%, y es claro el incremento que sufrió la LIJ, pasando a ser el 9,7\% de la producción total. A su vez, el 52,8 \% de la LIJ era traducido, y el resto original, con gran base etnográfica. La literatura suponía un $33 \%$ del total de lo publicado.

\section{2.c) Época contemporánea (1976-). Un panorama para el optimismo.}

La aprobación del Estatuto de Autonomía (1979) y del Decreto de Bilingüismo (1982) supusieron un vuelco radical en el sistema literario vasco, ya que posibilitaron que, por primera vez, el euskara fuera oficial junto al castellano y obligatorio en la enseñanza primaria y secundaria. Pero además, la nueva situación política permitió la aprobación de ayudas a la edición en euskara, con el consiguiente incremento de la producción editorial. Con una red de editoriales más asentada y abundante, el número de libros publicados en euskara se incrementó paulatinamente, pasando de publicarse una media de 31,5 libros por año en el período 1876-1975, a una media de 659,2 
libros/año, durante el período 1976-1994. En cuanto a la literatura infantil y juvenil, es llamativa la evolución que ha tenido en el porcentaje de la producción total. Si entre 1876-1935 sólo el 2, 4\% de lo publicado en euskara era LIJ, el porcentaje se incrementará a 9,8 \% entre 1936-1975 y al 23,1 \% entre 1976-1994. En la actualidad, un 20-25 \% del total de lo publicado en euskara es LIJ, y dentro de ella, un $50 \%$ son traducciones, un 30 \% reediciones y un $20 \%$ libros de nueva creación. Por tanto, cada año se editan 60-70 obras nuevas de LIJ en euskara y, si nos atenemos a los datos del 2002 (1.586 libros), vemos que se publicaron un total de 344 libros de LIJ. La tirada media es, por lo general, de unos 1.500-2.000 ejemplares. M. López Gaseni (2000) resume, de ese modo, las características de la LIJ traducida al euskara en este período: a) los libros traducidos en este período no son canónicos, sino que son elegidos de los polisistemas más próximos al vasco: el catalán y el castellano. La literatura canónica traducida al euskara no ha pasado a formar parte del canon de literatura vasca; b) las traducciones desde las lenguas originales no se han sucedido, de forma sistemática, más que a partir de los 90; c) al igual que en anteriores períodos, se tiende a simplificar las complejidades sintácticas y semánticas. Se trata de un período donde la LIJ traducida al euskara se produce de forma sistemática.

Por otro lado, no sería comprensible el incremento en la producción al que antes hacíamos alusión si no recalásemos en la importancia que tuvieron, a finales de los 70 , nuevas editoriales como Erein y Elkar, o las ediciones que vinieron de la mano de la editorial Hordago. Es en esos años cuando surge, impulsada por Erein, la revista que se convertirá en espacio de experimentación para diferentes generaciones de ilustradores: Ipurbeltz (1977). Esta revista, junto a la existente Kili-Kili (1966-68/1977-2003), o las posteriores Xirrixta (1992-1997)y Nanai (2000-) vino a llenar, en parte, lagunas manifiestas en nuestra oferta editorial. El listado de editoriales vascas se verá incrementado, en los 80 y 90 con la incorporación de editoriales de ámbito estatal que empezarán a publicar en euskara (SM-1986, Anaya-1987, Alfaguara-Desclée-1988, Edelvives-1989...). También será en los 80 cuando comiencen a surgir Premios literarios de LIJ que funcionarán como plataformas de lanzamiento para los escritores. Nos referimos al Premio Lizardi (1982-), al Premio Baporea-SM (1985-), o al Premio Bilintx (1986-). A todos ellos se les sumarán, en la década de los 90, el Premio Euskadi de Literatura Infantil y Juvenil, y el Premio Antonio María Labaien (1993). La LIJ de los 80 tendrá que hacer frente a la gran demanda que desde los centros educativos y centros de euskaldunización realizan los lectores. Es por ello que, durante años, los libros más reeditados en euskara hayan sido libros de LIJ. En cualquier caso, si algo resulta llamativo de la producción literaria de la época es la modernización y actualización de poéticas que se da en un breve lapso de tiempo. El realismo crítico (Chan el fantasma de M. Landa, 1984), la fantasía (Chuck Aranberri dentista baten etxean de B. Atxaga, 1980; La máquina de la felicidad de A. Lertxundi, 1988), el teatro vanguardista (Logalea zeukan trapezistaren kasua [El caso del equilibrista que tenía sueño], de B. Atxaga), son sólo algunas de las tendencias que ejemplifican esta renovación literaria. Sus protagonistas son autores e ilustradores que durante los años 80 se incorporaron a la hasta entonces breve nómina de creadores de LIJ. Nos referimos a escritores como,: Pello Añorga, Aitor Arana, Pako Aristi, Bernardo Atxaga, Enkarni Genua, Joxemari Iturralde, Mariasun Landa, Anjel Lertxundi, Manu López, Xabier Mendiguren, Joxean Ormazabal, Jesús Mari Olaizola “Txiliku”, Karlos Santisteban, Joanes Urkixo, .... o a ilustradores como: Asun Balzola, Juan Carlos Eguillor, Jesús Lucas, Jokin Mitxelena, Antton Olariaga, Jon Zabaleta...En cualquier caso, este listado de autores se verá ampliado, en la década de los 90, por nombres como: Yolanda 
Arrieta, Javi Cillero, Juan Kruz Igerabide, Felipe Juaristi, Karlos Linazasoro, Miren Agur Meabe, Fernardo Morillo, Jon Suarez, Patxi Zubizarreta ${ }^{6} . .$. , o por ilustradores como: Iñaki (Mattin) Martiarena, Elena Odriozola, Mikel Valverde, Agurtzane Villate. En cuanto a las características de la ilustración en la Euskadi actual, diremos, siguiendo a E. Uria (2000), que: a) es escasa la producción propia de libros de gran formato; b) aparecen como mayoritarias las fórmulas tendentes a la caricatura (alta expresividad de las líneas; introducción de las deformaciones con fines expresivos; humor más o menos ingenuo; códigos tomados de la tradición del cómic...) c) escasísima presencia de producción propia en libros dirigidos a prelectores.

El panorama contemporáneo que hemos tratado de perfilar en los párrafos precedentes presenta, por tanto, un sistema literario vasco asentado y con un dinamismo realmente reseñable. A los comentarios que hemos hecho en torno al aspecto de la producción, habría que añadirle unos breves apuntes referidos a aspectos como el de la mediación o recreación. No cabe duda de que si la literatura infantil y juvenil en lengua vasca goza en la actualidad de muy buena salud y presenta una oferta editorial de calidad, a ello ha contribuido no sólo la investigación que desde la universidad se ha realizado a través de las tesis doctorales, sino a la labor que desde asociaciones, organizaciones y medios de comunicación ${ }^{7}$ se ha promovido para canalizar el necesario debate en torno al hecho literario. La creación, en 1990, de Galtzagorri Elkartea, sección vasca de la OEPLI, ha ayudado a coordinar esfuerzos en torno a la promoción y difusión de la LIJ en lengua vasca. Como se recoge en su página web (www.galtzagorri.org), además de designar a los miembros del jurado para el Premio Euskadi de Literatura Infantil y Juvenil, y colaborar asiduamente con EuskaltzaindiaReal Academia de la Lengua Vasca en la designación de los miembros del jurado para el Premio Nacional de LIJ, ha organizado diversos congresos (Congreso de Cuentos populares (2001), Congreso Libros de Aventura (2003), Congreso de Poesía Infantil (2002)...), promovido concursos (Concurso de Escritor Joven (2002)...), colaborado en campañas y actividades de promoción, y editado una revista, Behinola (1999-), donde se recogen reseñas y críticas de las novedades editoriales. En realidad, Galtzagorri no ha hecho más que tratar de continuar y ampliar toda una serie de actividades que en la década de los 90 pusieron de manifiesto que la literatura infantil y juvenil en lengua vasca abordaba una nueva etapa. Nos referimos a la labor que el Haur Literaturaren Mintegia (Seminario de Literatura Infantil) de Eskoriatza, hoy dependiente de la Universidad Mondragón, comenzó e impulsó en la década de los 90 con revistas como Kukumira y Kukuluma, o a las publicaciones que recogieron nuevas orientaciones en torno a la LIJ en euskara (Haur Literatura (Labayru, 1993); Haur Literaturaren Inguruan (UEU-1993); Bularretik mintzora (1993, Erein) de J.K. Igerabide; Haur literatura euskaraz (1994, Labayru) de Seve Calleja). Podríamos decir que la LIJ en

6 Es reseñable que el número de mujeres escritoras en la LIJ en lengua vasca sigue siendo más bajo que en el de las literaturas vecinas, y que la imagen de la mujer que nuestra literatura da denota, a veces, un claro sesgo ideológico de tendencia sexista. Según un estudio realizado por X. Etxaniz (2001), el reducido número de protagonistas femeninas, la domesticidad de sus labores... no reflejan la realidad vasca actual.

7 Aunque la presencia de la crítica de LIJ es todavía muy reducida en los medios de comunicación vascos, no podemos dejar de mencionar el protagonismo que los autores y obras de LIJ en euskara han tenido en el único programa de literatura existente en la televisión vasca o ETB, el programa Sautrela (2000-), o las críticas que se han ido publicando en el único periódico íntegramente publicado en euskara: Berria, además de las secciones existentes en revistas como Egan. 
euskara ha comenzado a dar pasos para superar su lugar periférico en el actual sistema literario vasco, así como en el sistema literario del estado español ${ }^{8}$. Seguramente, el aspecto que todavía sigue siendo más débil entre nosotros sea todavía el de la recepción de dichas obras. Tal y como se ha tratado de demostrar en recientes estudios sociológicos (cf. Olaziregi, M.J.:2000), la lectura de literatura en lengua vasca sigue estando demasiado mediatizada por la obligatoriedad escolar. Por si eso fuera poco, los estudios realizados por el Gobierno Vasco revelan que los 100.000 vascoparlantes que se han incorporando en las últimas décadas al grupo de euskaldunes, no se han convertido en consumidores de literatura vasca, al menos, en la medida en que se esperaba.

\section{3) Actualidad de la LIJ en lengua vasca: eclecticismo ${ }^{9}$.}

Si tuviésemos que utilizar adjetivos para describir el actual panorama literario de la LIJ en lengua vasca, términos como "ecléctico" servirían para calificarlo adecuadamente. Y es que, al igual de lo que ocurre en la literatura vasca para adultos, las poéticas, tendencias, o tipologías textuales son realmente diversas en la LIJ contemporánea en lengua vasca. De hecho, la utilización de tipologías genéricas para describir incluso la trayectoria de algunos de los autores relevantes nos acarrearía más de un problema. Un claro ejemplo lo tenemos en la constante renovación que ha conocido la trayectoria de Mariasun Landa, quien, ha pasado del realismo crítico (Txan fantasma, 1984), a poéticas minimalistas (Iholdi, 1988), o a ofertas textuales que gustan de combinar el nonsense y la literatura del absurdo (Krokodiloa ohe azpian-Un cocodrilo bajo la cama,2003). Pero tendríamos las mismas dificultades para describir, por poner otro ejemplo, la trayectoria de Bernardo Atxaga. Decir que hace suyo el realismo fantástico, sería olvidar la importancia que otro tipo de tendencias, como por ejemplo, la metaficción historiográfica (la serie de Bambulo), o la hibridez de géneros (Alfabeto sobre la literatura infantil y juvenil, 1996) han tenido en su obra. Diríamos otro tanto de autores vascos contemporáneos canónicos, como, por ejemplo, Juan Kruz Igerabide, cuyos excelentes poemas y narraciones han conseguido seducir a propios y extraños (Poemas de la pupila, 1992: Hiperión; Botoi bat bezala/Como un botón, Anaya, 1999; Hosto gorri, hosto berde/ Hoja roja, hoja verde, 2002...Jonás y el frigorífico miedoso, Everest, 1998; ¡Agua va!(desde mi terraza), Edebé, 1997...), o Patxi Zubizarreta, quien ha demostrado que es capaz de escribir buenas novelas juveniles de aprendizaje o aventuras (El chico que fue hombre, 2000, Anaya...), así como cuentos de incuestionable intensidad poética (Paloma, llegaste por el aire, 1998, La Galera...), ...o autores de larga trayectoria como Anjel Lertxundi, quien sigue nutriéndose del realismo fantástico, la literatura oral y la metaficción en publicaciones recientes como el Cuaderno de tierra firme (Alfaguara, 2001), o Historias de la tierra incierta (Anaya, 2000).

Todos ellos, junto a las aportaciones de escritores reconocidos como Felipe Juaristi (autor de atractivas fábulas modernas: Ilargi lapurra, 1997; Animalien inauteria, 1999; o de textos novedosos como: El loro de Haydin, Everest, 2003), Miren Agur Meabe (autora de la novela de tintes góticos: La casa del acantilado,

\footnotetext{
${ }^{8}$ Véanse las consideraciones realizadas al principio de este artículo.

9 Para una presentación más detallada de los autores y tendencias actuales, se pueden consultar: López Gaseni, M. (coord.) et al.: 2004; Olaziregi, M.J.: 1999; 2002. Por otro lado, quisiera subrayar que el listado de obras que sigue pretende incorporar, ante todo, las traducciones al castellano de las originales en euskara.
} 
Edebe, 2004), Karlos Linazasoro (artífice de textos fantásticos como Bota gorriak/Las botas rojas, Anaya 2004), Javi Cillero (escritor que combina obras de realismo crítico como Eddy Merckxen gurpila, 1994, con relatos más fantásticos del tipo de: Thailandiako noodle izugarriak, 2001), o Joanes Urkixo, quien sigue acertando con novelas de aventuras como Gerlari zuria (O guerreiro blanc, Tándem, 2003; El guerreru blancu, Libros del Pexe, 2003), son exponentes de la renovación de la literatura infantil y juvenil vasca actual. Y ya que hablamos de renovación, no estaría de más subrayar que la mayoría de los textos y autores mencionados cumplen una cualidad que, según Z. Shavit (cf. Poetics of Children Literature, University of Georgia Press, 1986), incide en la innovación de la literatura infantil y juvenil. Nos referimos al hecho de que buscan un destinatario ambivalente. Es decir, son obras que no se dirigen exclusivamente al lector infantil, sino que tratan de satisfacer las expectativas literarias del lector adulto.

Vemos, por tanto, que el retrato actual de la literatura infantil y juvenil vasca presenta una producción donde el género narrativo tiene un gran protagonismo, y donde las propuestas literarias actuales enriquecen, en la medida en que la subvierten, la conocida distinción entre Obras fantásticas (relatos tradicionales, ciencia ficción, nonsense....) y Obras realistas (realismo crítico, aventura, narración histórica, narración policíaca...).

No quisiéramos terminar este breve repaso sin subrayar la importancia que, en las últimas décadas, ha cobrado el género poético en la producción literaria vasca. Tras el revulsivo que supuso la irrupción de J.K. Igerabide en el panorama literario vasco, se han sucedido, ininterrumpidamente, propuestas poéticas reseñables, como las de J.M. Irigoien (Metak eta kometak, 1994), J.A. Ormazabal (Hitzak jostailu, 1994; Txoko txiki txukuna, 1998), Y. Arrieta (Denboraren kanta-kontuak, 1995), Karlos Linazasoro (Hamabi titare, 1999), Igerasoro (Igerabide + Linazasoro: Kartapazioko poemak, 1998), Pello Añorga (Jiran-Biran, 1998), Jon Suarez (Ilbetea dilindan, 2002)...o cuidadas ediciones que incorporan poemas, adivinanzas, juegos...como Aixa mixa zilarra (Elkarlanean, 2000) de J.M. Olaizola “Txiliku”, o Mintzo naiz ixilik de J.K. Igerabide, (Elkarlanean, 2001). En cuanto al teatro, aunque recientes adaptaciones de obras de autores vascos (Landa, Atxaga, Arrieta...) han tenido muy buena acogida, la verdad es que la producción dramática sigue siendo muy reducida. El listado de autores que han publicado obras de teatro infantiles incluiría, entre otros, a: Marijane Minaberri (Haur antzerki, 1983); M. López Gaseni (Andoni eta Maddalenen komeriak, 1994), X. Diaz Esarte ( A zer nolako comería!, 1995; Mito, mito eta kitto, 1999), Y. Arrieta (Badago ala ez dago, 1998); Aitzpea Goenaga (Antzezten, teketen, ten, 1999), o propuestas dramáticas sugerentes como la que firman el escritor K. Uribe y el grupo musical Oskorri: Ekizazu, lehoiek ez dakite biolina jotzen (2003).

Sólo nos queda desear que el atractivo panorama actual de la literatura infantil y juvenil en euskara se vea enriquecido con la incorporación de nuevas lecturas, diálogos, en definitiva. 


\section{BIBLIOGRAFÍA.}

Etxaniz, X., Euskal Haur eta Gazte Literaturaren Historia, Iruña, Pamiela, 1997.

Etxaniz, X., "Ideología haur literaturan (emakumearen irudia gure haur eta gazte literturan)”, Egan 2001-1/2, 137-158.

López Gaseni , M., Euskarara itzulitako haur eta gazte literatura: funtzioak eraginak eta itzulpen-estrategiak, Bilbao, UPV-EHU, 2000.

López Gaseni, M.(coord.)et al. Panorama de la Literatura Infantil y Juvenil vasca actual. (Revista Behinola, 1999-2004), Galtzagorri Elkartea, 2004.

Olaziregi, M.J., “Mariasun Landa o la poética de la ternura”, Clij 122, 1999, 7-21.

Olaziregi, M.J., “Aproximación sociológica a los hábitos de lectura de la juventud vasca”, Oihenart 18, 2000, 79-93.

Olaziregi, M.J., Leyendo a Bernardo Atxaga, Servicio Editorial de la Universidad del País Vasco, 2002.

Torrealdai, J.M., Euskal Idazleak, Gaur, Aranzazu, Jakin, 1997.

Uria, E. “Algunas reflexiones para abordar la historia de la ilustración de la literatura infantil y juvenil. Aproximación a la ilustración en Euskal Herria”, in Actas del II. Congreso de Literatura Infantil y Juvenil. Historia Crítica de la Literatura Infantil e Ilustración Ibéricas, Ed. Regional de Extremadura, 2000, págs. 51-57. 